\title{
Effects of the Application of Computer Network Technology to Guided Discovery Teaching on Learning Achievement and Outcome
}

\author{
Desheng Lyu ${ }^{1^{\star}}$, Bei Wang ${ }^{2}$ \\ ${ }^{1}$ Key Laboratory of Interactive Media Design and Equipment Service Innovation, Ministry of Culture, Harbin Institute of \\ Technology, CHINA \\ 2 Harbin Normal University, CHINA
}

Received 31 January 2018 - Revised 29 April 2018 - Accepted 15 May 2018

\begin{abstract}
The development of computer and information technology has human society enter a brand-new information era. The most obvious change is that information becomes inevitable living focus in human life. The promotion of education reform in the world also has information education present the important status, expecting to train students' capability to grasp information and enhance the learning outcome with information technology. Eventually, they could learn the survival skills in the information society as well as promote national competitiveness. With quasiexperimental study, 252 students in Harbin Institute of Technology are proceeded 16week ( $3 \mathrm{hr}$ per week for total 48 hours) experimental teaching. The research results show that 1.guided discovery teaching would affect learning achievement, 2.guided discovery teaching would influence learning outcome, 3.learning achievement presents significantly positive effects on learning effect in learning outcome, and 4.learning achievement shows remarkably positive effects on learning gain in learning outcome. Finally, suggestions, according to the results, are proposed, expecting to provide thinking methods and direction for students' learning, encourage students to make deeper thinking, and help students establish learning achievement in the principle discovery process to enhance learning efficiency through the practice of computer network technology in guided discovery teaching.
\end{abstract}

Keywords: computer network technology, guided discovery teaching, learning achievement, learning outcome

\section{INTRODUCTION}

The development of computer and information technology in the end of $20^{\text {th }}$ century has human society enter a brand-new information era. Countries in the world made various plans to grasp high technology and acquire advantage on national literacy in order to develop the national power. In the information society, the advance of network communication and information in every level of life allows people interacting with each other through networks and computers for instantaneously and conveniently acquiring required information. The development of technology has human-computer communication become more easily that man-computer interface changes from keyboard, mouse, screen touch, to voice control. Information provided by computers is not simply restricted to texts, graphs, audio and video, but even 3D effect; the visual reality becomes more lifelike and popular. When education reform is promoted in the world, information education also presents the important status, expecting to train students' capability to grasp information with information technology to help them enhance learning outcome and learn the survival skills in the information society as well as promote national competitiveness.

To have students adapt to the complex modern society, educators promote various effective learning strategies, and discovery teaching promoted by educators could cultivate learners to discover, inquire, and solve problems, through discovery or creative learning, as well as independent thinking and creation \& invention abilities. Students

(C) 2018 by the authors; licensee Modestum Ltd., UK. This article is an open access article distributed under the terms and conditions of the Creative Commons Attribution License (http://creativecommons.org/licenses/by/4.0/). $\square$ deshengl@hit.edu.cn (*Correspondence) $\boldsymbol{W}$ wangb_harbin@126.com 


\section{Contribution of this paper to the literature}

- Teachers are suggested to analyze the contents of teaching units, list important concepts, and then inquire common teaching experiments or activity about the concepts.

- In consideration of student gap in the same class, teachers are suggested to apply cooperative learning to guided discovery teaching, group students heterogeneously, and have classmates with better degree assist those with bad degree in the learning.

- When teachers intend to change the teaching to be construct-oriented, they need the evaluation tool which could authentically reflect students' knowledge construction ability.

could actively and positively participate in the learning process and self-organize and construct knowledge. In other words, all knowledge is actively manipulated and interpreted by individuals, rather than passively acquiring knowledge. Accordingly, teachers being able to guide students, through problems, to make correct think and control the entire teaching situation to reduce mistake would reduce students' frustration caused by failure. This study therefore applied computer network technology to guided discovery teaching, aiming to provide students with learning thinking methods and direction, through the guidance of problems and peer interaction, encourage students making deeper thinking, help students establish learning achievement in the principle discovery process, and enhance the learning efficiency to further achieve learning transfer.

\section{LITERATURE REVIEW}

\section{Web-based Computer Instruction}

He et al. (2015) referred computer education to the education focusing on computers as the teaching tool or teaching computer skills; the coverage of information education was broader, including information processing concepts and methods as well as equipment related to computers. Mullis and Martin (2015) regarded computerassisted instruction or computer-assisted learning as teaching or learning with computers as the tool or medium. Personal computers used to be used for the practice, while assisted teaching and assisted learning in computer labs became popular after the emergence of regional network technology. Chua et al. (2015) indicated that the Internet showed far-reaching characteristics and rich resources, which could induce education scholars and educators utilizing the tools for supporting computer-assisted instruction and learning systems, i.e. distance teaching/learning. Huang, Chang, and Wu (2015) explained web-based instruction as applying the hypermedia and multimedia of World Wide Web (WWW) to create meaningful learning environment so as to enhance or assist in learning, aiming to cultivate learners' automatic learning habit. Borghese et al. (2015) positioned web-based learning as to proceed "teaching" and "learning", the two-way communication teaching, with various advantages of networks. Wu et al. (2016) considered web-based instruction as teachers and students being able to precede teaching preparation, practice teaching activity, evaluating and guidance in the Internet teaching environment. Although web-based teaching environment did not show traditional teaching structure, it presented infinite elearning space and contained rich e-libraries and increasing useful electronic data. Dolgin (2015) proposed that, in addition to text model, World Wide Web also presented multimedia of graphs and sound to attract most people to development on it. Nonetheless, even though there were lots of mature distance learning websites for interactive functions of material interpretation, assignment hand-in, achievement enquiry, billboards, and discussion, distance learning websites were still designed according to traditional teaching model. Xiong et al. (2017) stated that network could break through the fence of classrooms and schools for learning so that students could access distance education resources and courses without being restricted to distance as well as select online announcement, reading, or participating in discussion without being limited by time.

\section{Guided Discovery Teaching}

Hobday (2016) regarded guided discovery teaching as teachers interacting with students with problems and guiding students to discover important concepts with living problems, from old experiences to gradually getting into critical thinking and comprehensively evaluating learning activity, and connecting teaching with real life. Guided discovery learning therefore was to change traditional rules into lively and positive learning (Lam et al., 2016). Furthermore, Braithwaite et al. (2017) pointed out the characteristics of guided discovery teaching as students discovering problems, inquiring problems, and solving problems, like scientists. Such learning was to cultivate systematic inquiry ability and give scientific thinking opportunities at various stages, in which every thinking stage was the one-by-one development, to form the thinking learning cycle. Such teaching could train students' inductive and logic thinking and help establish good scientific attitudes. Accordingly, guided discovery teaching could guide students' active participation and induce some common points to help cultivate students' basic competency 
required for natural science (Nozari \& Siamian, 2015). Guggenheim and Williams (2015) considered that teachers, in the teaching process, guided students to discuss problems step by step and students found out problems according to facts and collect and verify data to make reasonable explanations, and solve problem for new knowledge. The proposed four stages (Daly, Bulloch, Ma, \& Aidulis, 2016) required the participation of students to provide scientific thinking opportunities. Hua et al. (2015) described the characteristics of guided inquiry teaching as students, like scientists, discovering problems, inquiring problems, solving problems, and seeking for solutions. Such learning was a systematic cultivation of inquiry ability to offer thinking opportunities at various stages; and, each thinking stage was the one-by-one development to form thinking learning cycle. Such teaching could train students' inductive and logic thinking and help establish good learning attitude.

\section{Learning Achievement}

Howard and Navarro (2016) referred learning achievement to learners, in specific learning environment, perceiving the intrinsic knowledge and achievement after learning through courses and materials. De Leeuw et al. (2016) described learning achievement as knowledge, comprehension, and skills acquired through special education experience with formal curricula and teaching design in schools, or an individual acquiring certain information and being familiar with certain skills through special teaching. Hua et al. (2015) pointed out learning achievement as what an individual could do academically, i.e. personal psychological capability performed on learning. Cadzow, Chambers, and Sandell (2015) mentioned that a lot of scholars regarded the close relationship between cognition in motivation \& attitude and learning achievement, i.e. being able to predict learning outcome with motivation cognition and behavioral attitude. Such research assumed students' willingness and expected value in motivation factors, cognition in attitude factors, and perception of problems as the factors in students' learning strategies. The practice of such learning strategies would affect learning achievement. Leo (2017) regarded bad learning motivation, bad attitudes, students' education attainment and career ambition, peer relationship, selfidentity, and appearance as major factors.

Referring to Cho, Shin, and Yu (2016), the following dimensions are proposed for learning achievement in this study.

(1) Socioeconomic status: Parents with higher education would be more willing to spend time for checking children's schoolwork, discuss learning experience, and instruct academic learning skills. Apparently, higher socioeconomic status shows strengths on children's learning.

(2) Peer relationship: It refers to individuals with similar ages exchanging experience and opinions, proposing questions, and questioning each other, through linguistic symbols and participation in activity, to construct personal thoughts and concepts.

(3) Learning skill: Learning skill (or learning strategy) is the method and route applied to learning. Learning skill allow students acquiring excellent performance at schools and benefiting lifelong. There are various types of learning skills applied to different occasions.

\section{Learning Outcome}

Learning outcome is generally the evaluation of learners after completing certain learning activity and the achievement of learning activity to the predicted effect (Lin \& Chen, 2016). Ding et al. (2016) pointed out the consistent concepts of academic performance, learning outcome, or learning achievement, i.e. students' learning result on school subjects or persistent results through learning process. Surjono (2015) regarded the indicator to evaluate students' learning outcome as the major item to evaluate teaching quality. Learning outcome would be affected by curriculum design, teaching method, and learning behavior, and students' learning objectives were to monitor self-learning, reflect learned knowledge, and learn how to learn. In this case, learning outcome was the direct presentation of learning result. Chassine, Villain, Hamel, and Daien (2015) indicated that evaluation of learning outcome was the collect of data and information about student abilities satisfying course objectives; such evaluation was practiced in the course and was normally preceded by the assignation of work. McCann and Marek (2016) regarded learning outcome as the indicator to measure students' learning result as well as the major item to evaluate teaching quality; such performance evaluation could stimulate and induce students' learning, and the evaluation result allowed students and teachers understanding the learning and teaching results for explaining or improving teaching effect.

Referring to Guo et al. (2016), two dimensions are covered in learning outcome in this study.

(1) Learning effect-containing test performance, schedule completion time, and term scores.

(2) Learning gain-including learning satisfaction, achievement, and preference. 


\section{Research Hypothesis}

Ding et al. (2016) regarded guided discovery teaching as giving instruction and guidance before or during students' inquiry, allowing students finding out answers in the inquiry process and encouraging students communicating the discovery; such teaching activity could help students comprehend the essence of knowledge and enhance students' learning achievement. Wong and Saw (2016) described the learning pattern of guided discovery teaching that instructors provided important basic data and proposed some questions to stimulate learners' interests and enhance learners exploring and thinking problem-solving methods. Zhou et al. (2017) explained such a teaching method allowing learners actively exploring knowledge as active explorers, rather than knowledge acceptors as in traditional teaching. In addition accumulating knowledge and learning problem-solving capability, such a method stressed on the thinking process in learning to effectively enhance students' learning achievement and allowed learners generating various concepts to enhance learning autonomy and generalization (Lam et al., 2016). The following hypothesis is therefore proposed in this study.

H1: Guided discovery teaching would affect learning achievement.

Guo et al. (2016) regarded guided teaching as the combination of leading organization and discovery learning for the synergistic effect that guided teaching was therefore generated. Xu, Wen, and Rissel (2015) explained that leading organization could cover new and old knowledge and provide the optimal cognitive anchorage at proper levels to establish subordinate and supervisor relationship between subsumers in new material concepts and learners' cognition structure. In other words, a cognitive bridge was built for meaningful learning to effectively enhance students' learning outcome. The characteristics of guided discovery teaching was to combine the spirit of discovery teaching with the consideration of real teaching schedule and train students problem-solving thinking habits and scientific attitudes. Teachers therefore had to design and arrange knowledge contents beneficial to students discovering "predicted learning" in real teaching situations and enhance students' learning outcome (Lin \& Chen, 2016). The following hypothesis is then proposed in this study.

H2: Guided discovery teaching would influence learning outcome.

Cho et al. (2016) indicated that the point to practice guided discovery teaching with computer network technology was to provide interactive learning and induce intrinsic learning motivation. Learners proceeded independent or group operation activity in the interactive environment; the peer communication and feedback of operation experience allowed students' pleasant learning and learning achievement to enhance learning outcome. Learning without sense of achievement would have students lose self-confidence, perceive pressure of academic work, and lack interests to form vicious circle to influence the learning attitude and not to enhance learning outcome (You et al., 2014). Leo (2017) indicated that the higher learning achievement would enhance interests, and learning achievement was the motive to achieve the goal. In this case, learning achievement would affect learning outcome. Accordingly, the following hypotheses are proposed in this study.

H3: Learning achievement shows significantly positive effects on learning effect in learning outcome.

H4: Learning achievement reveals remarkably positive effects on learning gain in learning outcome.

\section{RESEARCH METHOD}

\section{Measurement of Research Variable}

\section{Learning achievement}

Referring to Cho et al. (2016), learning achievement is divided into (1) socioeconomic status, (2) peer relationship, and (3) learning skill.

\section{Learning outcome}

Referring to Guo et al. (2016), it contains (1) learning effect and (2) learning gain.

\section{Research Object and Sampling Data}

With quasi-experimental study, 252 students in Harbin Institute of Technology are selected as the research object. The experimental class (126 students) is proceeded guided discovery teaching with computer network technology, while the control class (126 students) remains traditional teaching method. The experimental teaching is preceded 16 weeks for 3 hours per week (total 48 hours). The retrieved data are analyzed with SPSS, and Regression Analysis and Analysis of Variance are applied to test various hypotheses. 
Table 1. Analysis of Variance of the practice of computer network technology in guided discovery teaching on learning achievement

\begin{tabular}{cccc}
\hline variable & F & P & Scheffe post-hoc \\
\hline socioeconomic status & 10.238 & $0.000^{*}$ & guided $>$ general \\
\hline peer relationship & 13.467 & $0.000^{*}$ & guided $>$ general \\
\hline learning skill & 12.551 & $0.002^{*}$ & guided $>$ general \\
\hline *
\end{tabular}

* stands for $p<0.05$

Table 2. Analysis of Variance of the practice of computer network technology in guided discovery teaching on learning outcome

\begin{tabular}{cccc}
\hline variable & $\mathbf{F}$ & $\mathbf{P}$ & Scheffe post-hoc \\
\hline learning effect & 18.716 & $0.000^{*}$ & guided $>$ general \\
\hline learning gain & 15.931 & $0.006^{*}$ & guided $>$ general \\
\hline${ }^{*}$ stands for $p<0.05$ & & &
\end{tabular}

Table 3. Analysis of learning achievement to learning outcome

\begin{tabular}{|c|c|c|c|c|}
\hline \multirow{3}{*}{$\begin{array}{l}\text { dependent variable } \rightarrow \\
\text { independent variable } \downarrow \\
\text { learning achievement }\end{array}$} & \multicolumn{4}{|c|}{ learning outcome } \\
\hline & \multicolumn{2}{|c|}{ learning effect } & \multicolumn{2}{|c|}{ learning gain } \\
\hline & Beta & $\mathbf{t}$ & Beta & $\mathbf{t}$ \\
\hline socioeconomic status & 0.153 & $1.764^{*}$ & 0.167 & $1.898^{*}$ \\
\hline peer relationship & 0.178 & $2.045^{* *}$ & 0.184 & $2.096^{\star \star}$ \\
\hline learning skill & 0.202 & $2.237^{* *}$ & 0.211 & $2.344^{* \star}$ \\
\hline $\mathrm{F}$ & \multicolumn{2}{|c|}{21.158} & \multicolumn{2}{|c|}{26.434} \\
\hline significance & \multicolumn{2}{|c|}{$0.000^{\star \star \star}$} & \multicolumn{2}{|c|}{$0.000^{\star \star \star *}$} \\
\hline $\mathrm{R} 2$ & \multicolumn{2}{|c|}{0.189} & \multicolumn{2}{|c|}{0.231} \\
\hline Adjusted R2 & \multicolumn{2}{|c|}{0.164} & \multicolumn{2}{|c|}{0.192} \\
\hline
\end{tabular}

\section{ANALYSIS RESULT}

\section{Effects of the Practice of Computer Network Technology in Guided Discovery Teaching on Learning Achievement and Learning Outcome}

\section{Analysis of Variance of the practice of computer network technology in guided discovery teaching on learning achievement}

According to Analysis of Variance, the differences in the practice of computer network technology in guided discovery teaching on learning achievement is discussed in this study, i.e. analyses and explanations of socioeconomic status, peer relationship, and learning skill. From Table 1, the practice of computer network technology in guided discovery teaching shows significant effects on socioeconomic status $\left(\mathrm{P}=0.000^{*}\right)$, peer relationship $\left(\mathrm{P}=0.000^{*}\right)$, and learning skill $\left(\mathrm{P}=0.002^{*}\right)$ that $\mathrm{H} 1$ is supported.

\section{Analysis of Variance of the practice of computer network technology in guided discovery teaching on learning outcome}

According to Analysis of Variance, the difference in the practice of computer network technology in guided discovery teaching on learning outcome is discussed in this study, i.e. the analyses and explanations of learning effect and learning gain. From Table 2, the practice of computer network technology in guided discovery teaching reveals remarkable effects on learning effect $\left(\mathrm{P}=0.000^{*}\right)$ and learning gain $\left(\mathrm{P}=0.006^{*}\right)$ that $\mathrm{H} 2$ is supported.

\section{Correlation Analysis of Learning Achievement and Learning Outcome Correlation Analysis of learning achievement and learning effect}

To test H3, the analysis results, Table 3 , reveal notably positive effects of socioeconomic status $\left(t=1.764^{*}\right)$, peer relationship $\left(\mathrm{t}=2.045^{* *}\right)$, and learning skill $\left(\mathrm{t}=2.237^{* *}\right)$ on learning effect that $\mathrm{H} 3$ is supported. 


\section{Correlation Analysis of learning achievement and learning gain}

To test H4, the analysis results, Table 3, show significantly positive effects of socioeconomic status $\left(t=1.898^{*}\right)$, peer relationship $\left(\mathrm{t}=2.096^{* *}\right)$, and learning skill $\left(\mathrm{t}=2.344^{* *}\right)$ on learning gain that $\mathrm{H} 4$ is supported.

\section{CONCLUSION}

The research results show that guided discovery teaching could enhance students' learning achievement and learning outcome. When learners could not apply learned knowledge to solve new problems, effective prompts could activate the mind for learners grasping the potential structure of problems in the learning and approach proper information from teachers' guidance to extract relevant information from the memory. In the problems with similar structure, they could simulate the problem-solving and further explain logic thinking to achieve the learning effect. In this case, proper guidance could benefit discovery learning. By connecting learning materials and students' cognition structure in guided teaching, teachers provide a conceptual structure for students more stably combining and remaining detailed and differential materials, i.e. allowing students reorganizing information in the work memory to have the information present consistency for internal link as well as assist students in comparing the similarity and difference in the facts, concepts, and questions in the learning contents. The learning therefore is reorganized and integrated with existing knowledge. Such learning could help students apply the learned information to learning new materials. General teaching simply review the concept learned before. Although students notice new information, those with worse prior knowledge might transmit the learned information to the work memory, but could not combine it with present knowledge. Without internal link and external link, such information could merely be stored in long-term memory with the original state, but not being generalized to other similar learning situations. For this reason, students with general teaching appear worse learning achievement and learning outcome.

\section{SUGGESTION}

Aiming at above research results, the following suggestions are proposed in this study.

1. Teachers are suggested to analyze the contents of teaching units, list important concepts, and then inquire common teaching experiments or activity about the concepts, consider most students' existing knowledge and misconception on the concepts, rearrange the steps and sequence, and timely add problems which could induce students' thinking without frustration to enhance students' learning achievement. Meanwhile, students' inductive and logic thinking could be trained to help them establish good learning attitudes.

2. In consideration of student gap in the same class, teachers are suggested to apply cooperative learning to guided discovery teaching, group students heterogeneously, and have classmates with better degree assist those with bad degree in the learning. It would help the practice of guided discovery teaching.

3. When teachers intend to change the teaching to be construct-oriented, they need the evaluation tool which could authentically reflect students' knowledge construction ability. Similarly, teachers intending to change traditional pencil \& paper tests and make the evaluation be authentic should present correspondent teaching behavior to make teaching livelier and pay attention to the spirits of enquiry and knowledge construction. It is suggested that teachers could start on the change of teaching and slowly look for proper evaluation materials in the teaching, gradually increase the proportion of performance evaluation in pencil \& paper tests, and feedback the evaluation results to the teaching. In this case, it could improve teaching and evaluation effects.

\section{ACKNOWLEDGEMENT}

MOE (Ministry of Education in China) Project of Humanities and Social Sciences (Grant NO: 17YJAZH058)

\section{REFERENCES}

Borghese, M. M., Tremblay, M. S., Leduc, G., Boyer, C., Bélanger, P., LeBlanc, A. G., . . . Chaput, J. P. (2015). Television viewing and food intake during television viewing in normal-weight, overweight and obese 9to 11-year-old Canadian children: a cross-sectional analysis. Journal of Nutritional Science, 4, 8. https://doi.org/10.1017/jns.2014.72

Braithwaite, I., Stewart, A. W., Hancox, R. J., Murphy, R., Wall, C. R., Beasley, R., . . Group., I. P. T. S. (2017). Body Mass Index and vigorous physical activity in children and adolescents: an international cross-sectional study. ActaPaediatrica. https://doi.org/10.1111/apa.13903 
Cadzow, R. B., Chambers, M. K., \& Sandell, A. M. (2015). School-based obesity intervention associated with three year decrease in student weight status in a low-income school district. Journal of Community Health, 40(4), 709-713. https:// doi.org/10.1007/s10900-015-9989-0

Chassine, T., Villain, M., Hamel, C. P., \& Daien, V. (2015). How can we prevent myopia progression? European Journal of Ophthalmology, 25(4), 280. https:// doi.org/10.5301/ ejo.5000571

Cho, B. J., Shin, J. Y., \& Yu, H. G. (2016). Complications of pathologic myopia. Eye \& Contact Lens, 42(1), 9-15. https://doi.org/10.1097/ICL.0000000000000223

Chua, S. Y., Ikram, M. K., Tan, C. S., Lee, Y. S., Ni, Y., Shirong, C., . . Saw, S. M. (2015). Relative contribution of risk factors for early-onset myopia in young Asian children. Invest Ophthalmol Vis Sci, 56(13), 8101-8107. https:// doi.org/10.1167/iovs.15-16577

Daly, C. J., Bulloch, J. M., Ma, M., \& Aidulis, D. (2016). A comparison of animated versus static images in an instructional multimedia presentation. Advances in Physiology Education, 40(2), 201-205. https://doi.org/10.1152/advan.00053.2015

De Leeuw, R. A., Westerman, M., Nelson, E., Ket, J. C., \& Scheele, F. (2016). Quality specifications in postgraduate medical e-learning: an integrative literature review leading to a postgraduate medical e-learning model. BMC Medical Education, 16, 168. https:/ / doi.org/10.1186/s12909-016-0700-7

Ding, D., Lawson, K. D., Kolbe-Alexander, T. L., Finkelstein, E. A., Katzmarzyk, P. T., van Mechelen, W., \& Pratt, M. (2016). The economic burden of physical inactivity: a global analysis of major non-communicable diseases. The Lancet, 388(10051), 1311-1324. https:/ / doi.org/10.1016/S0140-6736(16)30383-X

Dolgin, E. (2015). The myopia boom. Nature (London), 519(7543), 276-278. https:// doi.org/10.1038/519276a

Guggenheim, J. A., \& Williams, C. (2015). Role of Educational Exposure in the Association between Myopia and Birth Order. JAMA Ophthalmology, 133(12), 1408-1414. https:// doi.org/10.1001/jamaophthalmol.2015.3556

Guo, L., Yang, J., Mai, J., Du, X., Guo, Y., Li, P., Zhang, W. H. (2016). Prevalence and associated factors of myopia among primary and middle school-aged students: a school-based study in Guangzhou. Eye (Lond), 30(6), 796-804. https:/ / doi.org/10.1038/ eye.2016.39

He, M., Xiang, F., Zeng, Y., Mai, J., Chen, Q., Zhang, J., . . Morgan IG. (2015). Effect of time spent outdoors at school on the development of myopia among children in china: A randomized clinical trial. JAMA, 314(11), 11421148. https:/ / doi.org/10.1001/jama.2015.10803

Hobday, R. (2016). Myopia and daylight in schools: a neglected aspect of public health? Perspectives in Public Health, 136(1), 50-55. https:/ / doi.org/10.1177/1757913915576679

Howard, T., \& Navarro, O. (2016). Critical Race Theory 20 Years Later: Where Do We Go From Here? Urban Education, 51(3), 253-273. https:/ / doi.org/10.1177/0042085915622541

Hua, W. J., Jin, J. X., Wu, X. Y., Yang, J. W., Jiang, X., Gao, G. P., \& Tao, F. B. (2015). Elevated light levels in schools have a protective effect on myopia. Ophthalmic $\mathcal{E}$ physiological optics, 35(2), $252-262$. https:// doi.org/10.1111/opo.12207

Huang, H. M., Chang, D. S., \& Wu, P. C. (2015).The Association between Near Work Activities and Myopia in Children-A Systematic Review and Meta-Analysis. PLoS One, 10(10). https:// doi.org/10.1371/journal.pone.0140419

Lam, M., Choi, M., Lam, H. R., Agarwal, A., Chow, R., Chow, S., . . Henry, B. (2016). Use of multimedia in patient and caregiver education for cancer pain management: a literature review. Annals of Palliative Medicine, 6(1), 66-72. https:/ / doi.org/10.21037/apm.2016.11.06

Leo, S. W. (2017). Current approaches to myopia control. Current Opinion in Ophthalmology, 28(3), $267-275$. https:/ / doi.org/10.1097/ICU.0000000000000367

Lin, J. Y., \& Chen, H. (2016). Effects of using multimedia situational teaching in establish nurse-patient relationship for new nurses. Studies in health technology and informatics, 225, 615-616.

McCann, F. \&Marek, E. (2016).Achieving Diversity in STEM: The Role of Drawing-Based Instruments. Creative Education, 7(15), 2293-2304. https:/ / doi.org/10.4236/ce.2016.715223

Mullis, I. V. S., \& Martin, M. O. (Eds.). (2015). PIRLS 2016 assessment framework (2nd ed.). Chestnut Hill, MA: TIMSS \& PIRLS International Study Center, Boston College.

Nozari, A. Y., \& Siamian, H. (2015).The effect of applying podcast multimedia teaching system on motivational achievement and learning among the boy students. ActalnformaticaMedica, 23(1), 29-32. https:/ / doi.org/10.5455/aim.2015.23.29-32

Surjono, H. D. (2015). The Effects of Multimedia and Learning Style on Student Achievement in Online Electronics Course. Turkish Online Journal of Educational Technology - TOJET, 14(1), 116-122. 
Wong, Y. L., \& Saw, S. M. (2016).Epidemiology of Pathologic Myopia in Asia and Worldwide. Asia-Pacific Academy of Ophthalmology, 5(6), 394-402. https:// doi.org/10.1097/ APO.0000000000000234

Wu, P. C., Huang, H. M., Yu, H. J., Fang, P. C., \& Chen, C. T. (2016). Epidemiology of myopia. Asia-Pacific Journal of Ophthalmology, 5(6), 386-393. https:/ / doi.org/10.1097/APO.0000000000000236

Xiong, S., Sankaridurg, P., Naduvilath, T., Zang, J., Zou, H., Zhu, J., . . Xu, X. (2017). Time spent in outdoor activities in relation to myopia prevention and control: a meta-analysis and systematic review. ActaOphthalmologica. https:// doi.org/10.1111/aos.13403

Xu, H., Wen, L. M., \& Rissel, C. (2015). Associations of Parental Influences with Physical Activity and Screen Time among Young Children: A Systematic Review. Journal of Obesity, 2015, 546925. https:/ / doi.org/10.1155/2015/546925

You, Q. S., Wu, L. J., Duan, J. L., Luo, Y. X., Liu, L. J., Li, X., . . Guo, X. H. (2014). Prevalence of myopia in school children in greater Beijing: The Beijing Childhood Eye Study. ActaOphthalmologica, 92(5), e398-e406. https:// doi.org/10.1111/aos.12299

Zhou, Z., Chen, T., Wang, M., Jin, L., Zhao, Y., Chen, S., . . Congdon, N. (2017). Pilot study of a novel classroom designed to prevent myopia by increasing children's exposure to outdoor light. PLoS One, 12(7), e0181772. https:/ / doi.org/10.1371/journal.pone.0181772

\section{http://www.ejmste.com}

